\title{
INEEL PORTABLE VAPOR GENERATOR OPERATIONS AND MAINTENANCE MANUAL
}

\author{
G. L. Gresham \\ S. D. Hartenstein \\ Y. M. Leppert \\ P. Mottishaw \\ Published July 1997 \\ Idaho National Engineering and Environmental Laboratory \\ Lockheed Martin Idaho Technologies Company \\ Idaho Falls, Idaho 83415
}

DSTABUTON OF THIS DOCMENT is IFMMTED

Prepared for the

U.S. Department of Energy

Under DOE Idaho Operations Office

Contract DE-AC07-94ID13223 


\section{DISCLAIMER}

This report was prepared as an account of work sponsored by an agency of the United States Government. Neither the United States Government nor any agency thereof, nor any of their employees, make any warranty, express or implied, or assumes any legal liability or responsibility for the accuracy, completeness, or usefulness of any information, apparatus, product, or process disclosed, or represents that its use would not infringe privately owned rights. Reference herein to any specific commercial product, process, or service by trade name, trademark, manufacturer, or otherwise does not necescarily constitute or imply its endorsement, recommendation, or favoring by the United States Government or any agency thereof. The views and opinions of authors expressed herein do not necessarily state or reflect those of the United States Government or any agency thereor. 


\section{DISCLAIMER}

Portions of this document may be illegible electronic image products. Images are produced from the best available original document. 


\section{CONTENTS}

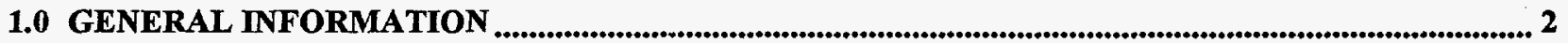

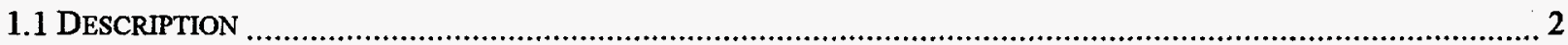

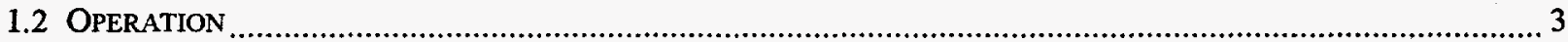

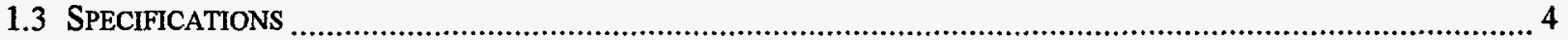

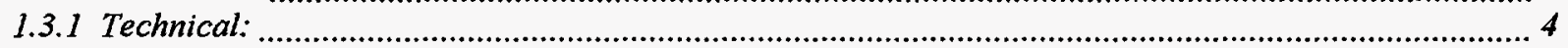

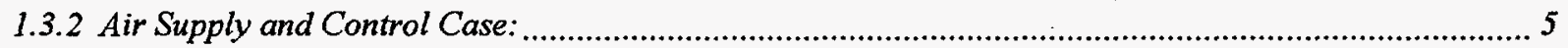

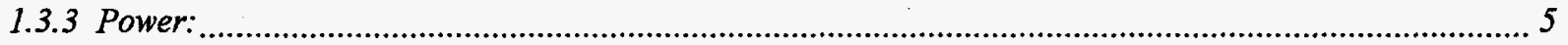

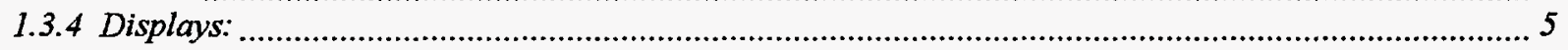

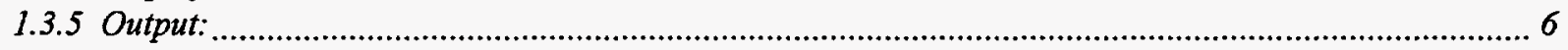

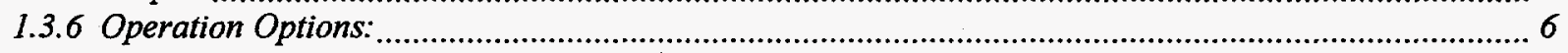

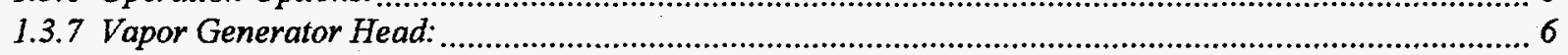

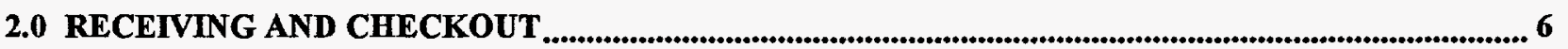

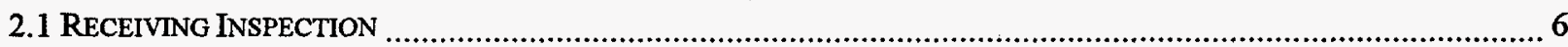

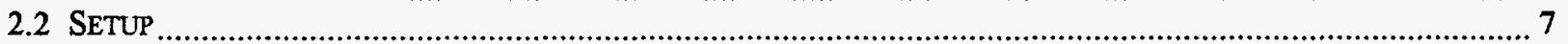

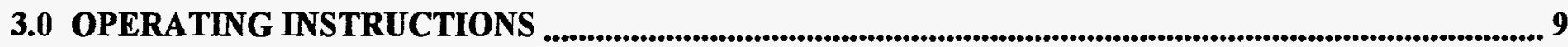

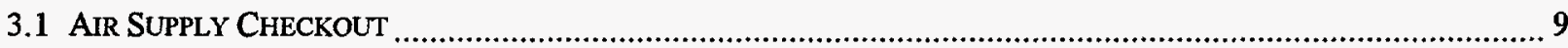

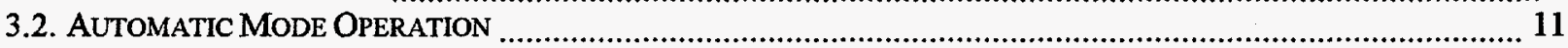

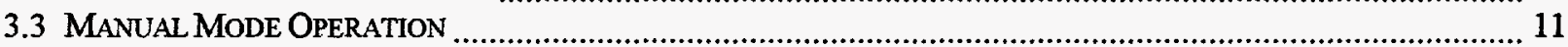

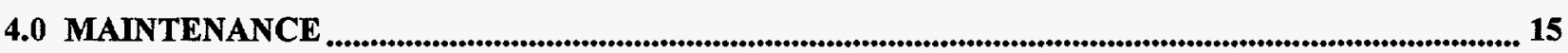

5.0 TROUBLESHOOTING

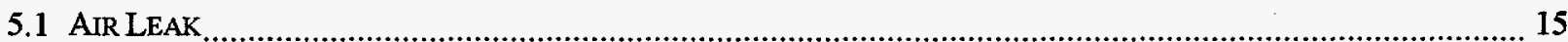

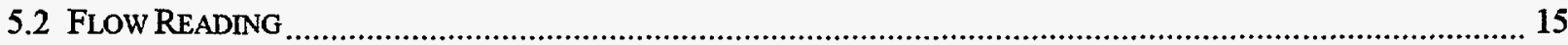

5.3 HEAD PRESSURE.

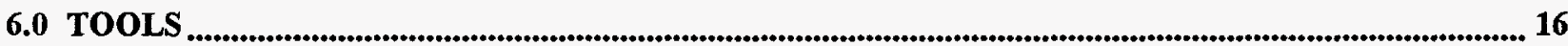

\section{FIGURES}

Figure 1 - Major Components of the INEL Vapor Generator $\ldots \ldots \ldots \ldots \ldots \ldots \ldots \ldots \ldots \ldots \ldots$

Figure 2 - INEL Vapor Generator Exhaust Head Components $\ldots \ldots \ldots \ldots \ldots \ldots \ldots \ldots \ldots \ldots$

Figure 3 - Vapor Generator Control Unit $\ldots \ldots \ldots \ldots \ldots \ldots \ldots \ldots \ldots \ldots \ldots \ldots \ldots \ldots \ldots$

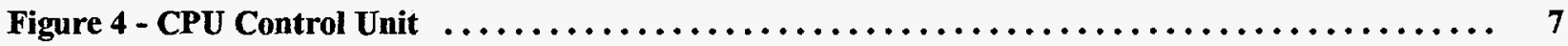

Figure 5 - Clean Air Supply Control Unit $\ldots \ldots \ldots \ldots \ldots \ldots \ldots \ldots \ldots \ldots \ldots \ldots \ldots \ldots \ldots \ldots$

Figure 6 - Vapor Generator Operator Screens ........................... 14 


\subsection{GENERAL INFORMATION}

\subsection{Description}

The Idaho National Engineering and Environmental Laboratory (INEEL) has developed a calibrated vapor generator, which delivers reproducible vapor aliquots of a standard in the picogram to low nanogram range. The basic system design includes a) a reservoir that contains the target analyte, $b$ ) a head, which contains the equipment (valves, filters, transducers) necessary to use the reservoir, and c) a controller assembly that contains the CPU, pump, and air filtering system. Figure 1 shows the basic system.

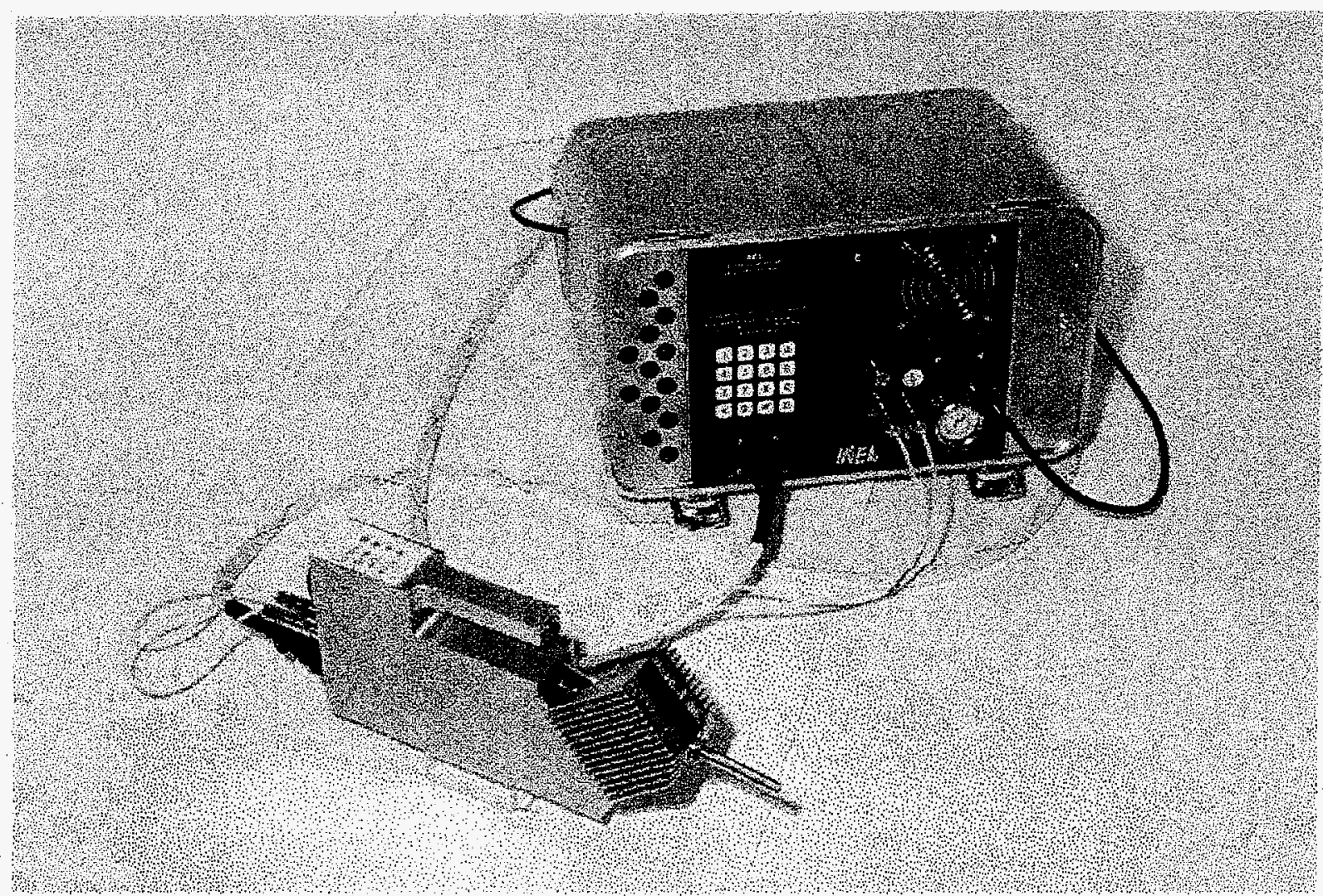

Figure 1 - INEEL Vapor Generator

Each vapor generator head consists of a reservoir, valves to control the air flow, filters, and pressure transducers necessary to obtain the desired flow pulse (Figure 2). Pulse initiation can be performed from either the head or the controller assembly. 


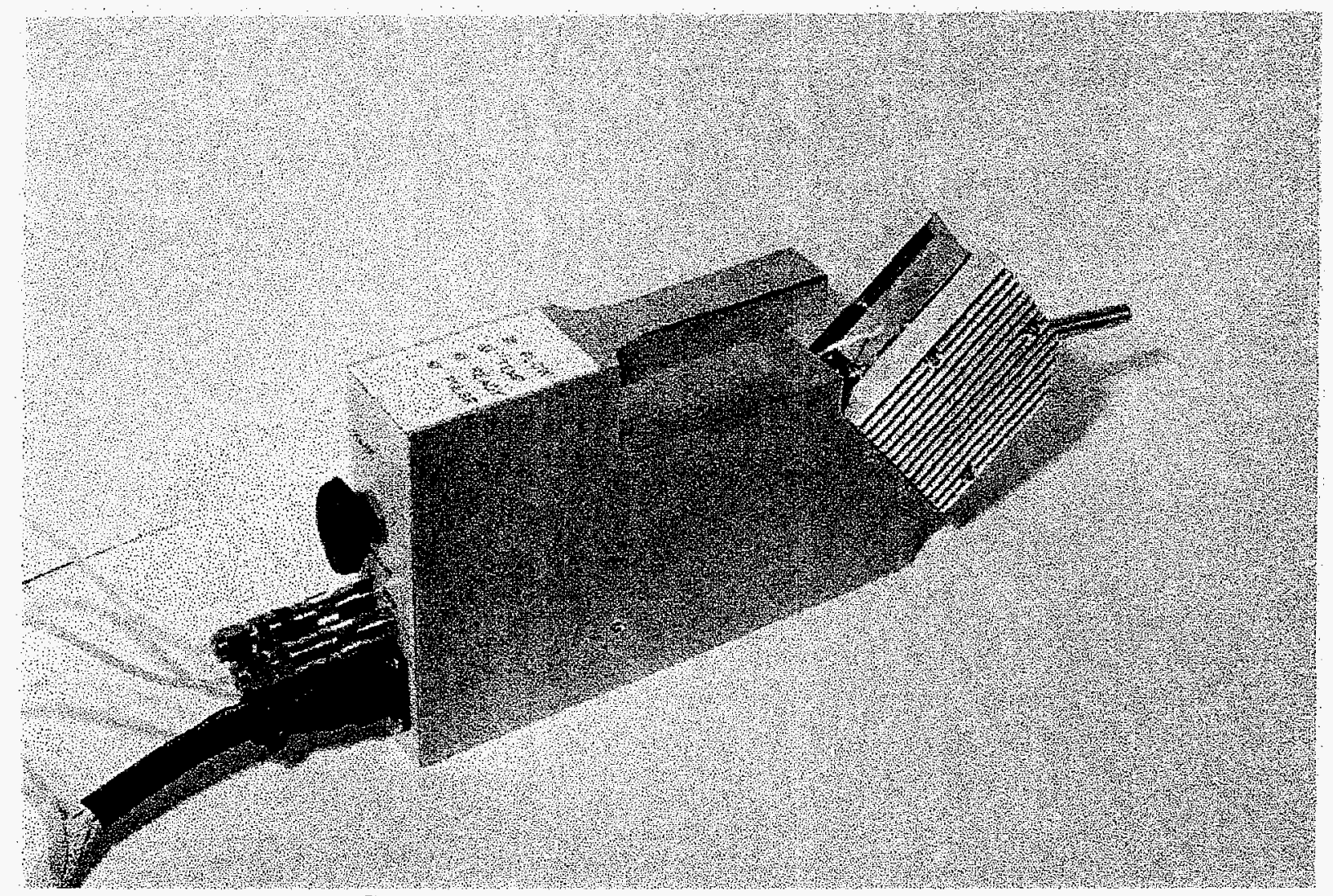

Figure 2 - INEEL Vapor Generator Head Components

The reservoir consists of a known quantity of target or analyte material (i.e., explosive, narcotic, etc.) dissolved in a solvent and deposited on an inert substrate (e.g., glass wool, stainless steel beads, etc.), which is located in a stainless steel block. The reservoir temperature is controlled via thermal electric cooler to generate a level of saturation of the target analyte in the reservoir. Each reservoir contains only a single target analyte; therefore, each analyte has its own complete head.

The controller houses a small computer that performs all of the control functions. Also included in the controller are the power supplies, an air pump, a pressure regulator, air filters, flow controllers, and displays.

\subsection{Operation}

The INEEL portable vapor generator can be operated in either the automatic or manual modes. The vapor generator controls the operating variables for temperature, air flow, and pulse width (sec.). In the manual mode, each of these variables can be set independently for operation. The automatic mode uses the results from a programmed calibration of the vapor generator for the computer to automatically control the variables to give the desired mass output of target analyte vapor. The desired output is entered in picograms, and the computer sets the temperature, flow, and pulse width from a calibration program curve for each type of vapor target analyte and head. 
The system can be converted to the continuous flow mode by a manual three-way valve.

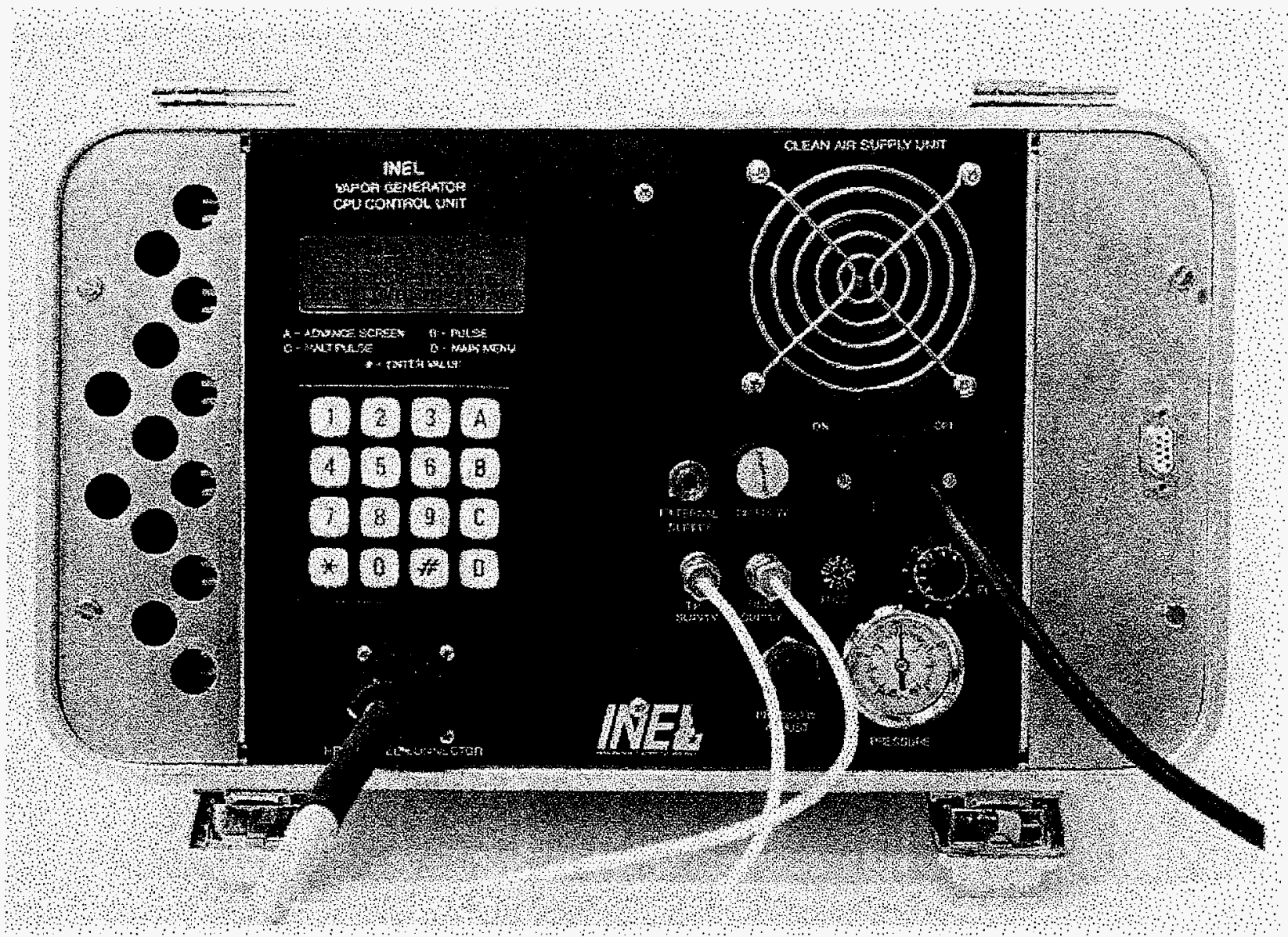

Figure 3 - Vapor Generator Control Unit

\subsection{Specifications}

The following are the specifications for a portable vapor generator:

\subsubsection{Technical:}

- Calibration requirements - calibrate once per year. (Each head for each controller at customer request.)

- Concentration range - 50-1000 picograms at vapor generator head outlet

- Repeatability $= \pm 20 \%$ RSD

- External CPU Access Plug 
- Reservoir temperature variable from $0^{\circ}-80^{\circ} \mathrm{C}$ (dependent on head configuration)

- Temperature control $= \pm 0.1^{\circ} \mathrm{C}$

- Pulsed air flow fixed between 50-200 ccm

- Continuous Air Flow

- Flow measurement coefficient of variation $<5 \%$

- Pulse width variable from 1-100 seconds

- Minimum time between pulses - 10 seconds

- Maximum pressure of controller pressure regulator $-20 \mathrm{psig}$

- In-line absorbent trap to prevent upstream contamination

- Design life - 5 years (2 hour/day duty cycle) [maybe less for generator heads using thermoelectric coolers]

\subsubsection{Air Supply and Control Case:}

- Detachable head

- 15-foot umbilical cord connects the vapor generator head to the controller

- Size - controller 16"x 16"x 9, shipping box 191/2"x 191/2"x 13"

- Weight - $30 \mathrm{lbs}$. without head

\subsubsection{Power:}

- 110 volt $\mathrm{AC}$ power (cord length $6 \mathrm{ft}$.)

\section{3:4 Displays:}

- Digital readout in picograms

- Ready light indicators: flow, temperature, and pulse 
- Menu selection (LCD)

- Flow rates (LCD)

- Gauge (controller) PSI

- Head PSI (LCD)

\subsubsection{Output:}

- An analog or digital output for data acquisition system to allow diagnostics

\subsubsection{Operation Options:}

- Entry of mass output (picograms)

- Starting sequence from the vapor generator head or the controller unit

- Manual or automatic operation modes

- Pulsed or continuous flow

\subsubsection{Vapor Generator Head:}

- Maximum temperature on outside surface $-49^{\circ} \mathrm{C}$

- Weight - 5 lbs.

- Size - maximum 61/4"x 12"x 6"; shipping box (three head capacity) 24"x 15"x $10 "$

\subsection{Receiving and Checkout}

\subsection{Receiving Inspection}

Step 1 Upon receipt of the vapor generator, perform the following inspections:

1) Inspect the head and controller shipping cases for physical damage

2) Open the cases and inspect the control panels, for damage

3) Remove the heads and inspect for damage 
4) Check to see if all components are included; shipping container, controller, one control cable with two air hoses, three vapor generator heads, and three outlet nozzles (one for each head).

Step 2 If damage is evident, notify the carrier and shipper with a description and ask for advice on returning the instrument for repair.

Step 3 Remove any packing materials and save for reshipment.

\subsection{Setup}

Step 1 Open the controller shipping case and remove the control cable with the two air lines and the 110 power cord.

Step 2 Attach the control cable (28 pin) to the connector on the controller (located on the front panel). See Figures $1 \& 4$.

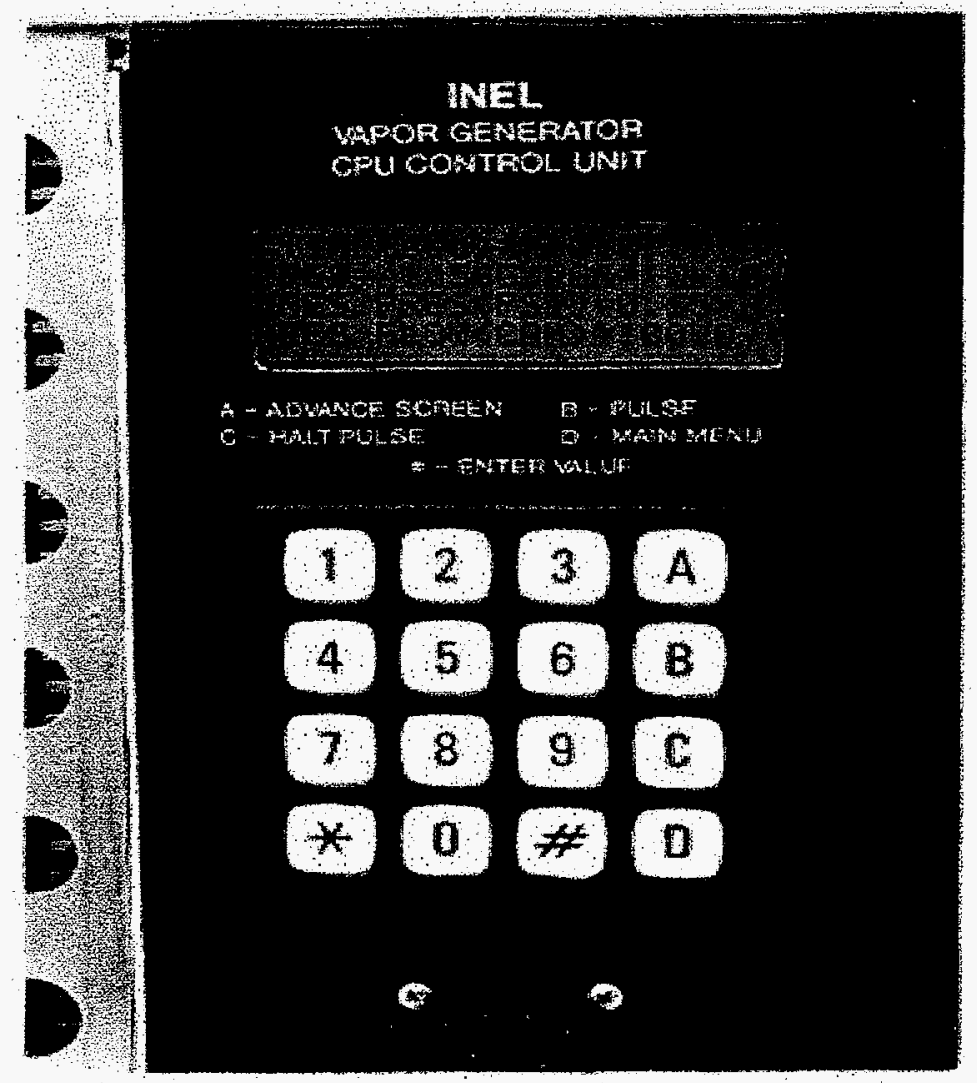

Figure 4 - CPU Control Unit. 
Step 3 Attach the black connector to black quick disconnect for tip air flow. Attach the two air lines to the quick disconnect fittings on the Clean Air Supply Unit panel, see Figure 5.

Step 4 Attach unmarked connector to unmarked quick disconnect for the reservoir flow.

Step 5 Attach the power cord to the control assembly by plugging into the 110 volt receptacle located on the Clean Air Supply Unit panel, see Figure 5. Plug the power cord into a 110 volt $\mathrm{AC}$ outlet.

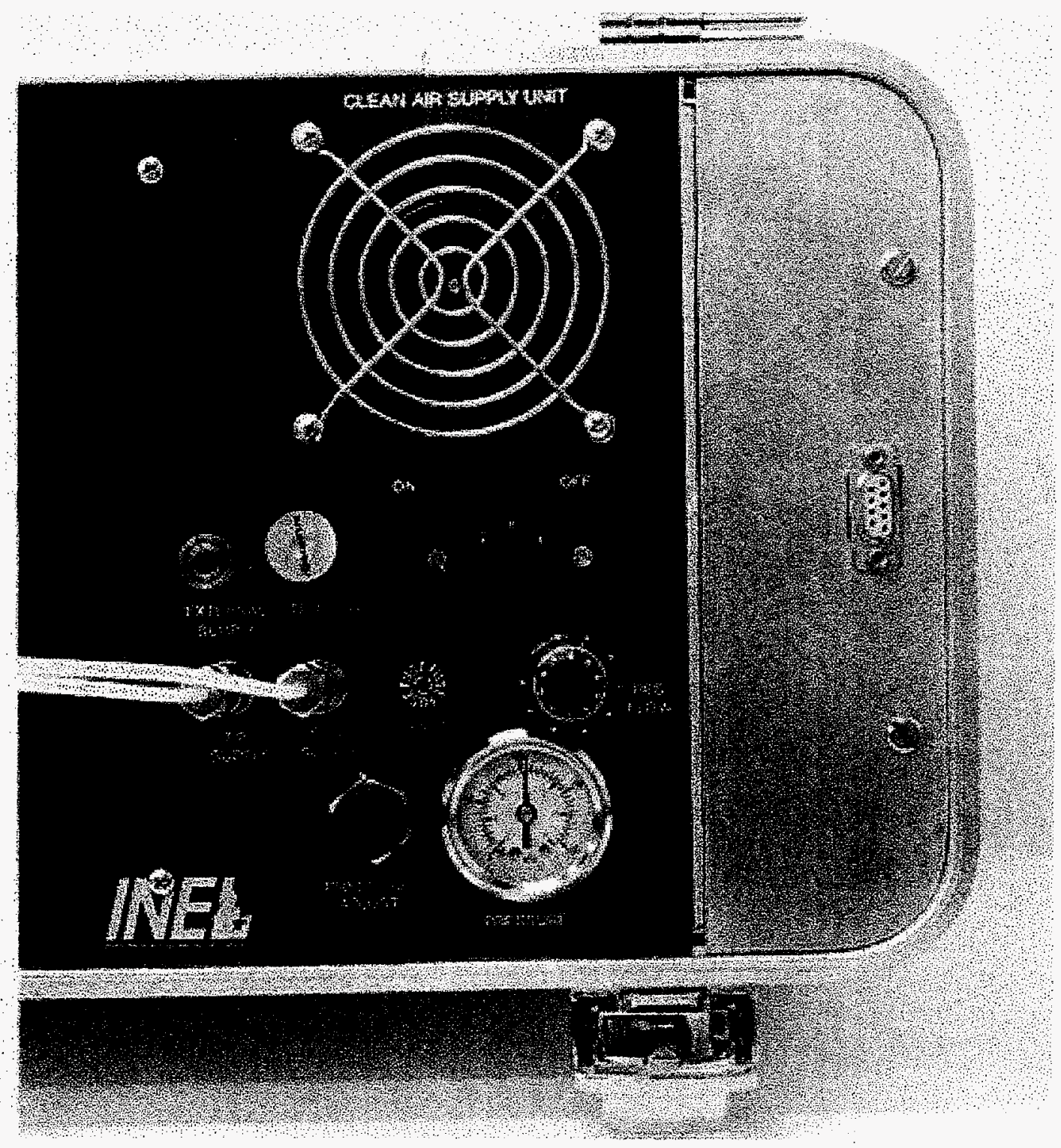

Figure 5 - Clean Air Supply Control Unit. 
Step 6 Remove the threaded plug from the vapor generator head outlet and place in a clean plastic bag. Install the outlet tip to the head by screwing the tip into the outlet of the vapor generator head (Vitron O-ring must be in place on tip). Tighten just snug (Caution: Do not over tighten).

Step 7 Connect the 28-pin control cable to the vapor generator head.

Step 8 Connect the two air lines to the vapor generator head. Attach the black connector to black quick disconnect for the tip flow and unmarked connector to unmarked quick disconnect for the reservoir flow.

Step 9 If external supply is used, hook up external supply line to external supply fitting.

Step 10 Adjust tip flow to desired flow as indicated using an external flow meter.

\subsection{Operating Instructions}

The INEEL Portable Vapor Generator can be operated in either an automatic or manual mode. Operation in the automatic mode uses the computer to set and control the temperature, the flow, and the pulse time to output the desired mass. The resulting pulse is based on the results of the internal system calibration program; the operator only needs to input the desired mass output in picograms.

In the manual mode, the operator must determine the mass output of the vapor generator head. It is recommended that an independent measurement of mass delivered be performed for the manual mode.

\subsection{Air Supply Checkout}

Prior to entering either the automatic or manual modes, the air supply system should be checked for leaks. This is accomplished by checking the flowmeter under no flow conditions using the following procedure:

Step 1 Turn on the 110 volt power supply, see Figure 5 and wait for the main menu to appear on the screen of the CPU control unit.

Step 2 Select the manual mode of operation from the main menu display by pressing 1, see Figure 6.

Step 3 Using the next screens in the manual mode set the flow, temperature, and pulse time as follows: 
A) The first screen in the manual mode is used to set the flow and is called the flow screen. Enter the flow as $200 \mathrm{ccm}$. Press the \# key to accept the setting (if the \# key is not pressed the setting reverts back to the default setting) and then A to advance to the next screen.

B) The second screen in the manual mode sets the temperature. Enter the temperature for the substance in the reservoir: a) $\mathrm{RDX}-51^{\circ} \mathrm{C}$, b) PETN $-48^{\circ} \mathrm{C}$, or c) TNT $-13^{\circ} \mathrm{C}$. Press the \# key to accept the setting and then A to advance to the pulse time screen.

C) The third screen in the manual mode sets the time the flow is passed through the reservoir or the pulse time. For this checkout, the pulse time is used by entering 999 , then pressing the \# key to accept the setting, and then A to advance to the next screen.

Step 4 The screen will now appear. During the initial energizing of the system, a pause is built into the system.

Step $5 \mathrm{Next}$ is the auto zero screen. Verify that the flow is within $0 \pm 3 \mathrm{ccm}$ and then press A. If flow is not within the specified range, check for air leaks and repeat steps 3.1.1 through 3.1.5.

Step 6 Press A after the auto zero to start the air supply pump. At this time, verify that the pressure on the pressure gauge is between 10 to 15 psi and then adjust the flow to $200 \pm 1$ $\mathrm{ccm}$ using the flow adjustment knob (Figure 5). Flow should be adjusted to within $\pm 1 \mathrm{ccm}$ of the setpoint before a pulse can be made.

Step 7 When the flow is set, lock the flow adjustment and press A to advance to the run screen.

Step 8 Disconnect both air hoses at the Clean Air Supply Unit (Figure 5). The connector has a check valve which allows the air supply system to be checked for air leaks. If the flow does not drop to $0-3 \mathrm{ccm}$, a leak is present. See Section 5.0 for troubleshooting procedures and begin the Air Supply Checkout procedure again.

Step 9 Reconnect the air supply hoses at the CPU control unit and disconnect both hoses at the head. After allowing the process to stabilize, the flow reading should be $<3 \mathrm{ccm}$. If the flow is not $<3 \mathrm{ccm}$, see Section 5.0 for troubleshooting procedures and begin the Air Supply Checkout procedure again.

Step 10 Reconnect the air supply hoses to the head.

Step 11 The following steps shall be performed either in a hood or in a plastic bag to trap the vapors: a) plug the reservoir outlet with clean tin foil and the shipping plug, b) initiate flow from the run screen by pressing $\mathrm{B}, \mathrm{c}$ ) wait 20 seconds and then decrease the 
system pressure by turning the pressure control knob three turns counter-clockwise, $d$ ) record the pressure and then wait 10 minutes and record the pressure again. The end pressure should be $>8 \mathrm{psig}$. If the pressure is $>8 \mathrm{psig}$, the air supply system is working properly. (If the pressure is $<8 \mathrm{psig}$, troubleshoot per Section 5.0.)

Step 12 Unplug the reservoir outlet and press $C$ to clear the air valve.

\subsection{Automatic Mode Operation}

Automatic mode is the calibrated mode of the vapor generator. All temperatures and flows are set and controlled by the computer. The following describes the operational procedure for the automatic mode:

Step 1 Turn on the 110 AC power switch (Figure 5).

Step 2 Select automatic mode from the display by pressing 0 at the main menu (Figure 6); the screen will appear after a short pause allowing the system to stabilize.

Step 3 At the auto zero screen, verify that the flow is $<3 \mathrm{ccm}$ and then press A. Pressing A after the auto zero starts the pump. (If flow is not $<3 \mathrm{ccm}$, go to Section 3.1, Air Supply Checkout.)

Step 4 Verify that the pressure is between 10 and 15 psi and then adjust flow using the flow adjustment $\mathrm{knob}$ to within $3 \mathrm{ccm}$ of the setpoint (normally $200 \mathrm{ccm}$ ).

Step 5 When the flow is set, press A to advance to the Set Pulse Mass screen.

Step 6 Set the mass by keying in the number of picograms desired in each delivered pulse, press the \# key, and then press A to advance to the run screen.

Step 7 To start a pulse, press B or the push button on the head (Figure 2). Pulses can be repeated; however, there is a set delay of at least 10 seconds between pulses. Any pulse can be stopped by pressing $C$. After an automatic pulse is completed, the display screen will display vapor generator flow, time, picograms, and temperature variables.

Step 8 To shut down from the automatic mode, use the power on/off switch (Figure 5). The system can be shut down from any menu.

\subsection{Manual Mode Operation}

Manual mode is used for special cases, e.g. continuous flow. It should be noted that the calibration is not valid for manual operation. The procedure for manual flow is as follows: 
Step 1 Turn on master switch (Figure 5).

Step 2 Select manual mode operation from the main menu by pressing 1 (Figure 6).

Step 3 The next screens set flow, temperature, and pulse time as follows:

A) The first screen sets the air flow. Enter the desired flow if different from the default flow (The default flow is obtained from the calibration). Press the \# key to enter the new flow setting and then A to advance to the next screen.

B) The next screen sets the temperature. Enter the desired temperature. Press the \# key to enter the new setting and then A to advance to the pulse time screen.

C) The pulse time screen allows one to select the length of time of air flow or can be set to operate in the continuous flow mode as follows:

- If the "pulse/continuous" head is used, and continuous flow is desired, switch designator knob to Continuous setting. To operate in pulse mode, turn switch to Pulse setting.

- For older style heads, enter the desired pulse time. Once the time is entered, press the \# key and then A to advance to the next screen.

Step 4 The screen will now appear and will perform the initial stabilizing of the system. The system must stabilize before the next screen will appear (a pause will occur).

Step 5 Next, the flow auto zeroing screen appears. This screen determines the flow offset so that the computer can use the results for zeroing the meter. This operation is done automatically by the system. Verify that the flow is $0 \pm .1$ units and then press A.

Step 6 Pressing A after the auto zero starts the pump. At this time, verify that the pressure is between 10 to $15 \mathrm{psi}$ and then adjust the flow using the flow adjustment knob, see Figure 5. Flow must be adjusted to within $1 \mathrm{ccm}$ of the set point before a pulse can be made. When the flow is set, press A to advance to the run screen.

Step 7 All pulses are made from the run screen. Prior to making any pulse, verify that the flow is correct. To start a pulse, press B or the push button on the head handle (Figure 2). Any pulse can be stopped by pressing $C$.

Step 8 To check or change the setpoints, press $D$, which returns you to the initial menu to repeat the sequence (starting with Step 3.3.2).

Step 9 To change flow, temperature, or time setpoints press D. Select 3 and follow settings below: 
a) select 0 if calibration or default settings are desired

b) select 1 if retention of the last set values is desired (manual mode)

c) select air supply and press A

Return to Step 3.A or manual mode operations.

Step10 To shut down from the manual mode, use the on/off switch on the Clean Air Supply Unit (Figure 5). The system can be shut down from any menu. 


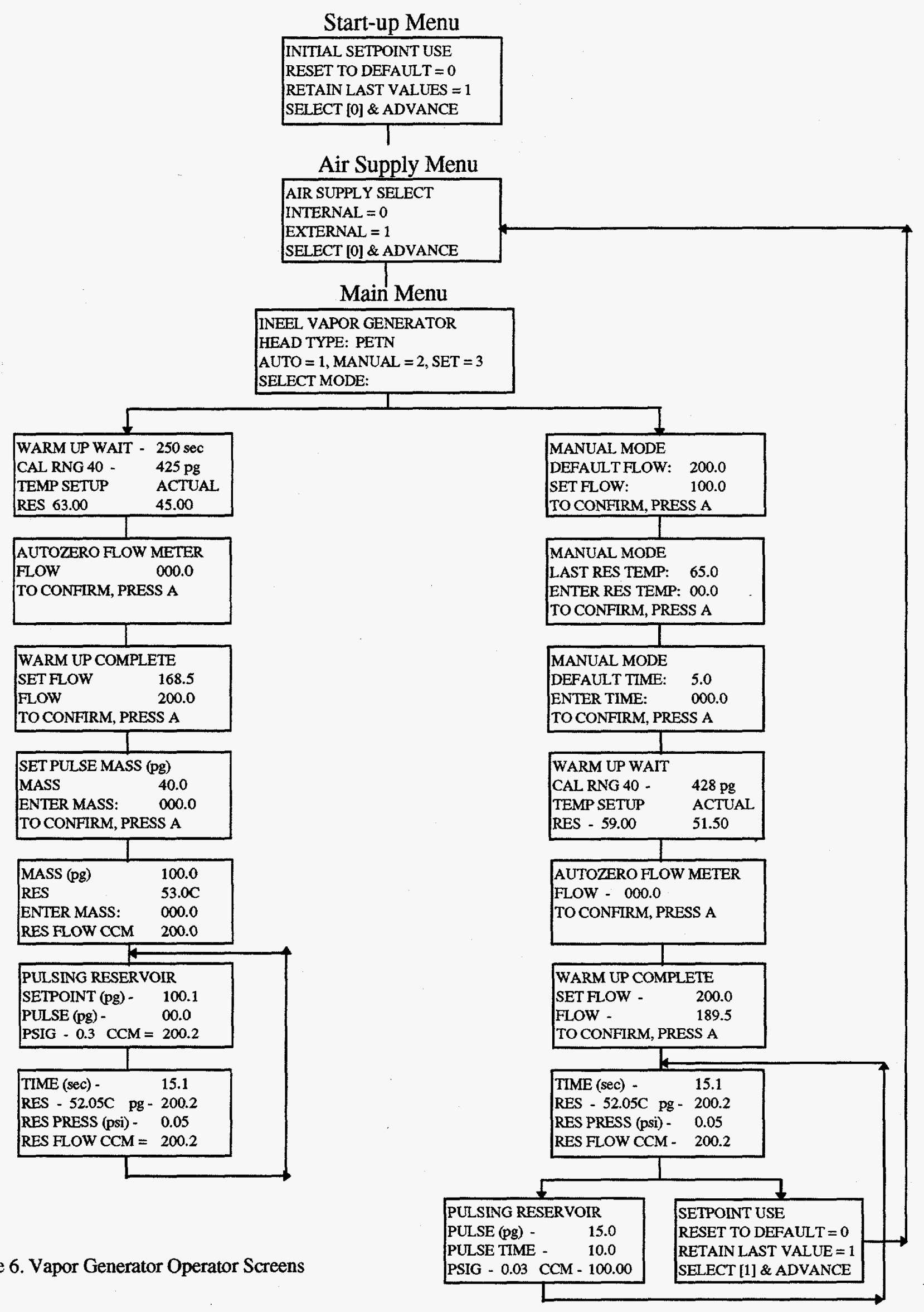




\subsection{Maintenance}

The following should be performed for normal maintenance of the vapor generator:

- $\quad$ Replace the Drierite/14x molecular sieve when the color indicator turns pink.

- Replace the activated charcoal filter in the control assembly case after 100 hours of operation.

- Clean/wipe surfaces weekly, tighten screws and check cords and air lines approximately every two months.

- Bake boundary layer tip at least once per week, or as needed. (NOTE: Do not use solvents to clean.)

\subsection{Troubleshooting}

\subsection{Air Leak}

If an air leak is suspected, check quick-disconnect and all Swagelok nuts for tightness. If nuts are secure/tight, and flow still does not drop to $0-3 \mathrm{ccm}$, contact the Principal Technician at the number listed below.

\subsection{Flow Reading}

If flow reading is not less than $3 \mathrm{ccm}$, check for cord/air line damage, or check quick-disconnect stems and bodies to ensure check valve is operating correctly (not stuck). If problems persist, contact the Principal Technician at the number listed below.

\subsection{Head Pressure}

If the pressure is less than $8 \mathrm{psig}$, check tightness of all fittings. Ensure filter O-ring is compressed or check tightness of the Cajon nut on the pressure transducer. Ensure shipping plug is tight. Call the Principal Technician if pressure is still unsatisfactory.

Maintenance and troubleshooting questions should be addressed in writing to: Idaho National Engineering and Environmental Laboratory, Lockheed Martin Idaho Technologies Co., FAA Project Manager, North Holmes Lab, P.O. Box 1625, Idaho Falls, Idaho 83415-2070. Or call Paul Mottishaw, Principal Technician, (208) 525-0683 or Steve Hartenstein, FAA Project Manager, (208) 526-1967. 


\subsection{Tools}

- Flow Meter (one that can be interfaced with the 3/8" O.D. of the tip.

- Flat Blade Screwdriver

- Phillips Blade Screwdriver

- 7/16", 1/2" End Wrench

- Medium Crescent Wrench 